\title{
Notas sobre o atual estatuto conceitual do dinheiro inconversível*
}

\author{
Gustavo Moura de Cavalcanti Mello ${ }^{* *}$
}

\begin{abstract}
Resumo
O fim da conversibilidade do dólar em ouro deu azo a um importante debate entre teóricos marxistas, em torno da atual natureza do dinheiro inconversível. Tendo em vista a especificidade da análise marxiana acerca da gênese, da essência e dos papéis desempenhados pelo dinheiro no interior da dinâmica da acumulação de capital, um ponto chave do debate diz respeito à sua atual validade. Constata-se que expressiva parte das interpretações marxistas acabam por se ater a determinações específicas e parciais do conceito de dinheiro, dissociando-o do conceito de capital. Em oposição a essa tendência, neste artigo procuramos apresentar relevantes "passos" desse conceito, para na sequência, à luz do evolver histórico, realizar uma breve incursão crítica pelo debate marxista contemporâneo em torno do tema, devotando atenção sobretudo às contribuições brasileiras. Esforça-se aí em apontar as virtudes e as deficiências de certas abordagens representativas, e se identifica nas análises de Prado (2013, 2016a, 2016b) um caminho para a solução de algumas controvérsias.
\end{abstract}

Palavras-chave: Dinheiro; Dinheiro inconversível; Capitalismo contemporâneo; Capital fictício; Teoria marxiana do valor.

\begin{abstract}
Notes on the current conceptual status of inconvertible money

The end of the convertibility of the dollar into gold gave rise to considerable debate among Marxist theorists, regarding the current nature of money (devoid of substance). In view of the specificity of the Marxian analysis about the genesis, the essence and the roles of money within the dynamics of accumulation of capital, a key point of debate concerns its current validity. It is noted that a significant number of the Marxist interpretations remain close to specific and partial determinations of the concept of money, dissociating it from the concept of capital.The present article, in opposition to this trend, shows the relevant "steps" of this concept, to sequentially, in light of the historical evolve, carry out a brief critical incursion by the contemporary Marxist debate around the subject, devoting particular attention to Brazilian contributions. We strive to point out the virtues and deficiencies of certain representative approaches and identify, in analyses carried out by Prado (2013, 2016a, 2016b), a path towards the solution to some of the controversies.
\end{abstract}

Keywords: Money; Inconvertible money; Contemporary capitalismo; Fictitious capital; Marx's theory of value.

JEL B51, E40, P16.

* Artigo recebido em 21 de janeiro de 2015 e aprovado em 21 de julho de 2017. Gostaria de agradecer as críticas e sugestões feitas pelos pareceristas anônimos e também pelos colegas do Departamento de Economia da UFES e do Grupo de Estudos sobre Dinheiro Mundial e Financeirização, também da UFES. Por se tratar de um texto finalizado anteriormente, boa parte delas não foram incorporadas ao texto, mas servirão de baliza para futuros estudos, que muito se valerão das profícuas discussões do referido grupo.

** Professor do Departamento de Economia e do Programa de Pós-Graduação em Política Social da Universidade Federal do Espírito Santo, Vitória, ES, Brasil. E-mail: gustavo.m.mello@ufes.br. 


\section{Introdução}

O chamado fechamento da "golden window" por Nixon e a consequente manutenção do dólar como moeda mundial, agora "livre" do lastro que mantinha com o ouro, desafiaram certas perspectivas teóricas. Mesmo no campo marxista propugnou-se que tal acontecimento colocou na berlinda a conceituação marxiana acerca do dinheiro, tornando premente sua atualização. Sabendo que o trabalho abstrato é a substância do valor, como compreender a atual natureza do dinheiro mundial, aparentemente desprovida de qualquer valor? Não se trata de uma questão escolástica. Ao encará-la, buscaremos demonstrar que o seu esclarecimento contribui com a compreensão do sistema monetário internacional ora vigente, assim como dos impactos causados pela reafirmação do dólar como dinheiro mundial sobre o sistema interestatal e sobre o (literalmente explosivo) desenvolvimento do sistema financeiro nas últimas décadas.

Parte-se do pressuposto, por conseguinte, que a abordagem marxiana é relevante para a apreensão conceitual da forma dinheiro - a despeito de seu longo, tortuoso e inacabado processo de teorização -, e é a tal abordagem que dedicaremos a primeira e a segunda sessão do artigo. Depois delas, serão debatidas questões teóricas ainda em aberto no interior do marxismo acerca do hodierno estatuto conceitual do dinheiro. A parte subsequente consiste na exposição das teses de Prado (2013, 2016a, 2016b), que traz importantes contribuições ao debate, e por fim, serão feitas algumas considerações finais.

\section{0 dinheiro no âmbito da circulação simples}

Como se sabe, em Para a crítica da economia política e em $O$ Capital, o caminho trilhado para a exposição do conceito de dinheiro (que não estava de todo ausente nos Grundrisse), foi o da apresentação de sua gênese lógica por meio da análise sobre o desenvolvimento das formas relativa e equivalente do valor, que corresponde ao movimento da contradição interna à mercadoria entre o valor e o valor de uso, a qual precisa se exteriorizar por meio da troca (Marx, 1996a, p. 212) ${ }^{1}$. A elevação do ouro e da prata à condição de dinheiro foi um resultado histórico, que redundou da "congruência de suas propriedades naturais com suas funções" monetárias (ibd, p. 214; Marx, 1977, p. 45), dando origem à já mencionada formapreço (Marx, 1977, p. 73-76; Marx, 1973, p. 65, 123; Marx, 1996a, p. 225). Também aqui aprendemos de saída que o dinheiro responde à necessidade de comparação e de permutabilidade de objetos qualitativamente distintos, enquanto valores de uso,

(1) As evidências e conexões entre a exposição lógica e a história do dinheiro, enfatizadas por Marx, foram contestadas por diversos estudiosos, na esteira de De Roover (1942) e de Usher (1943), entre outros. Recentemente, em sentido similar, adquiriu certa repercussão o livro de Graeber (2011). De acordo com a interpretação aqui exposta, os equívocos mais propriamente historiográficos e antropológicos que podem ser imputados a Marx não comprometem o rigor lógico de sua conceituação da forma-dinheiro especificamente capitalista. 
mas também, enquanto valores, à necessidade de diferenciação qualitativa frente ao próprio valor da mercadoria. É por isso que a "conversão" da mercadoria em tempo de trabalho não pode se dar de maneira imediata, e sim por meio de um representante universal desse tempo. Não obstante, se o dinheiro é expressão da contradição interna à mercadoria, se é o meio pelo qual tal contradição pode se mover (ibd, p. 227), ele acaba por repô-la sob novas formas, de maneira mais geral, universal (e mais explosiva) (Marx, 1977, p. 77). Nesse processo, está posta sua autonomização, o desenvolvimento do fetichismo do dinheiro (Marx, 1973, p. 96; cf. Marx, 1977, p. 51), ao que retornaremos adiante.

Nos Grundrisse, por sua vez, antes de considerar suas determinações, Marx expôs a necessidade do dinheiro argumentando que "o próprio valor real [...] nega a si próprio e constantemente põe o valor real das mercadorias em contradição consigo próprio, depreciando ou apreciando constantemente o valor das mercadorias já produzidas" (Marx, 1973, p. 62). Dessa maneira, o preço é a necessária forma de manifestação do valor por meio da mercadoria que serve de equivalente geral - fruto de um trabalho particular, mas que em função da dinâmica mercantil adquire portanto um valor de uso social -, mas opera não por meio de sua identidade imediata com o valor; ao contrário, ambos se adéquam mediante constantes inadequações e oscilações em torno de um "centro de gravidade", determinado pelo valor. Convergem assim apenas acidentalmente, num movimento pendular, no interior de um processo que envolve não apenas a produção imediata, mas o conjunto do processo concorrencial capitalista, que incessantemente revoluciona a produtividade do trabalho (ibd, p. 62). Já aqui, por conseguinte, tem-se indicada a unidade contraditória entre produção e circulação, que encontra no dinheiro um importante elemento mediador, e que, na condição de "cristal de valor" e de expressão universal de valor, constitui um amortecedor das incessantes alterações no valor das mercadorias. A mediação efetuada pela forma-preço é exigida pela especificidade do valor; sendo esse dado pelo trabalho abstrato objetivado, medido pelo tempo, ele não pode ser expresso nesse mesmo tempo de trabalho. Logo, é inerente à forma preço a "possibilidade de uma incongruência entre o preço e a grandeza de valor", que a torna "adequada a um modo de produção em que a regra somente pode imporse como lei cega da média à falta de qualquer regra" (Marx, 1996, p. 226), um modo de produção essencialmente contraditório e desequilibrado.

Convém recordar, logo de saída, que a exposição marxiana consiste não em uma narrativa histórica, e tampouco numa construção ideal a priori, mas na articulação conceitual de múltiplas determinações de seu objeto - a forma capital - a partir de seu fundamento contraditório, o que pressupôs um não menos intenso esforço investigativo, buscando apreender os nexos internos do capital em seu movimento e desenvolvimento imanentes (Marx, 1973, p. 20-29; Marx, 1996a, p. 140). Esse caráter contraditório do capital faz com que ele construa distintos níveis 
de existência, que se negam e se constituem reciprocamente e de maneira desigual; no âmbito da circulação simples de mercadorias, sabe-se que a mercadoria emerge como unidade contraditória de valor e de valor de uso, havendo a tendência à subsunção do último pelo primeiro, à sua redução à condição de suporte do valor. E o mesmo vale para a substância do valor, o trabalho abstrato, em relação à "fonte" do valor de uso, o trabalho concreto. Para mover-se, essa contradição precisa se exteriorizar e se generalizar, e, como mencionado, por meio do processo de troca uma mercadoria "empresta" seu corpo como meio de expressão do valor da outra, e é do desenvolvimento das assim criadas forma valor relativa e equivalente que se apreende o movimento de expulsão de uma (ou mais) mercadoria específica do reino das mercadorias, a qual adquire o valor de uso social de equivalente geral (ibd, p. 165-195). Assim, como universal concreto, adquirindo "existência autônoma exterior às mercadorias" (Marx, 1973, p. 123), ou ainda, existindo acima e ao lado das mercadorias particulares, o dinheiro se "distancia" de sua matéria, processo que logo se desdobra na possibilidade de sua substituição por um mero signo, bem como em outros desenvolvimentos que logo serão considerados. O avanço da exposição logo revela que a "verdade" da esfera da circulação simples se encontra na produção imediata, e que a mercadoria e o dinheiro são formas de manifestação do capital, cuja reprodução em escala ampliada é o fundamento, o motor e a finalidade última das formações sociais capitalistas.

A tendência contraditória à autonomização e à subjetivação do capital, acompanhada pela ocultação e mistificação de seu fundamento contraditório marca os mais diversos momentos da exposição de $O$ Capital, e se exprime, por exemplo, na generalização da forma-salário (que torna opaca a fronteira entre o tempo de trabalho necessário e o tempo de trabalho excedente); nas categorias de capital fixo e circulante, determinadas pelo modo de rotação dos elementos produtivos, e não pelo modo de participação na produção de valor, bem como na copertinência e nas contradições entre os ciclos do capital-monetário, do capital-mercadoria, e do capital produtivo (Carcanholo; Nakatani, 2001; Sabadini, 2013), no bojo da circulação do capital social total. Sobretudo, tal tendência se manifesta no âmbito do processo global de capital, em que a distribuição da mais-valia passa a ser determinada predominantemente pela propriedade, de modo que capitalistas que empregam seu capital de modo improdutivo participam legitimamente do butim (Grespan, 2011). Em meio a esse complexo e rigoroso construto categorial, que corresponde ao movimento de constituição do capital como totalidade contraditória, e que se dá por sucessivas negações, cada momento da exposição é ao mesmo tempo posto e pressuposto do seguinte. Cada categoria conserva momentos de verdade que irão fundamentar os objetos e as etapas subsequentes da apresentação, que, por sua vez, num repuxo, determinam retroativamente as categorias anteriormente postas, ao mesmo tempo em que tendem a dominá-las. Em consonância com essa perspectiva, como se verá, no bojo do movimento desmedido da acumulação a referência metálica 
(o fundamento "racional" do dinheiro) ergue-se como uma barreira à valorização, que o capital busca superar por meio de sua autonomização, expressa na generalização do dinheiro inconversível. Da mesma forma, da perspectiva do capital portador de juros e do capital fictício - em que o fetichismo do capital atinge seu ápice (Marx, 1986, p. 11; Marx, 1984a, p. 294; e Marx, 1980, p. 1496) -, o próprio processo de produção se afigura como uma barreira inaceitável ao movimento da acumulação. Em suma, a autonomização, a subjetivação e a mistificação do capital correspondem por conseguinte ao seu conceito (como é particularmente evidenciado na crítica marxiana à "fórmula trinitária" da economia vulgar) (Marx, 1986, p. 269280). Não obstante, argumentar-se-á que tal autonomização impõe a reposição, em outras bases, daquilo que tende a negar.

Consideremos brevemente as determinações fundamentais do dinheiro, de modo a apreender a relação entre sua substância, seu conteúdo material e seus suportes, e sua forma. Como medida de valores o dinheiro tem a função de expressar de modo unitário o valor de cada mercadoria particular (Marx, 1996a, p. 219), por comungar em conjunto com as mercadorias a condição de "cristal de valor". Notese que, para tanto, sua presença física é dispensável, e de fato o dinheiro não se faz presente aqui em sua realidade reluzente, ou em qualquer outra forma palpável, mas apenas idealmente (ibd, p. 220-221), servindo de moeda de conta: sua qualidade enquanto "cristalização" de trabalho abstrato é o dominante nessa determinação (Marx, 1973, p. 123, 138).

Por outro lado, nessa primeira determinação o dinheiro precisa existir ainda como um padrão de preços (Marx, 1996a, p. 222; Marx, 1977, p. 77). À época de Marx, o valor de cada mercadoria havia de se manifestar idealmente em certa quantidade de ouro ou prata, medida por seu peso; historicamente, fez-se necessário dividir sistematicamente a unidade desse peso em partes alíquotas, perfazendo assim um padrão que era tanto mais eficaz quanto mais estável. A criação e a manutenção dos padrões de preço eram, então, prerrogativas do Estado, assumindo, portanto, realidades nacionais; porém, se por um lado a função de padrão de preços possuía um conteúdo convencional e arbitrário, já que o Estado se encarregava de definir tal padrão e, com base nele, de controlar a cunhagem das moedas; por outro, sua necessidade se impunha no cotidiano das relações mercantis (ibd, p. 78, 107; Marx, 1996a, p. 246). Não obstante, dimana daí a ilusão convencionalista, segundo a qual o preço do metal precioso seria estimado em sua própria matéria, e fixado pelo Estado (ibd, p. 225; Fausto, 1997, p. 75-85). Ao contrário, Marx lembra que o dinheiro expressa o preço de todas as mercadorias, na medida em que este possui, como elas, valor, mas o próprio dinheiro não tem preço; a forma de manifestação do valor não pode ela mesma ser expressa em preço (Marx, 1977, p. 79; Marx, 1973, p. 142; Marx, 1996a, p. 220). A consolidação do padrão de preços e o controle da emissão de moedas são condicionados por férreas leis econômicas, relativas à 
produção e à circulação de mercadorias, e não se reduzem ao arbítrio da "autoridade monetária"; a despeito de possuir, cabe reiterar, um conteúdo convencional e arbitrário $^{2}$.

Se como medida de valores o dinheiro tem papel apenas ideal, para a efetivação das relações mercantis ele precisa se fazer presente, na condição de meio de circulação ou de troca, tendo como referência o padrão de preços estabelecido (Marx, 1996a, p. 239; Marx, 1977, p. 107). À medida que o próprio preço das mercadorias surge assim como exterior e mediado, encontramo-nos a um passo da inversão fetichista que faz com que o dinheiro pareça determinar unilateralmente os preços das mercadorias, cuja circulação, por sua vez, parece existir como resultado e em função da circulação do dinheiro (ibd, p. 217; Marx, 1977, p. 74; Marx, 1973, p. 124). Ademais, nesta segunda determinação, enquanto meio de circulação, é a quantidade de dinheiro que importa (ibd, p. 143), mas sua posição aqui é evanescente: na medida em que se interpõe viabilizando o intercâmbio de duas mercadorias, e que constitui sua garantia, o dinheiro se esvai como meio de circulação (ibd, p. 144). Por conseguinte, a pretensão universalizante presente no conceito de dinheiro é negada em sua determinação enquanto meio de circulação; assim, "para realizar o preço, sua existência material como ouro e prata, é essencial; mas na medida em que esta realização é somente evanescente e está destinada a suprimir-se, essa matéria é indiferente" (ibd, p. 144-145).

É dessa indiferença que advém a possibilidade de substituição do ouro e da prata por meros signos de valor (ibd, p. 146-148), isto é, como meio de circulação o dinheiro não atua de maneira ideal ou imaginária, tendo ao contrário que se fazer materialmente presente; mas isso não significa que deva se fazer presente em sua própria matéria. Assim, "sua existência funcional [como meio de troca] absorve, por assim dizer, sua existência material. Reflexo objetivado evanescente dos preços das mercadorias, funciona apenas como signo de si mesmo e, por isso, pode ser substituído por outros signos" (Marx, 1996a, p. 249). Tem-se aí um importante afastamento entre o dinheiro e sua matéria, que conduziu tantos pensadores a tomar o dinheiro como mero signo, e a tratar do valor dos metais preciosos e mesmo do conjunto das mercadorias como algo estritamente imaginário, "produto arbitrário da reflexão dos homens" (ibd, p. 214-215). Em meio a essa explicação lógica para o referido descolamento entre o dinheiro em sua função de meio de circulação e sua matéria metálica, Marx realiza “digressões históricas” (ibd, p. 246-247; Marx, 1977, p. 113), expondo um processo que encontra sua culminância na substituição das

(2) Longe de se desconsiderar o papel desempenhado pelas autoridades monetárias, poder-se-ia falar, valendo-se do jargão econômico, do seu caráter endógeno (Mollo, 1999), o que remete à análise da forma social capital como totalidade contraditória, tendo no Estado um de seus momentos essenciais, que se faz presente no cotidiano das relações econômicas, das mais elementares às mais complexas, e é parte ativa em diversos momentos do processo global de produção de capital. 
moedas metálicas por papel-moeda, cuja emissão perfaz uma prerrogativa do Estado - valendo exclusivamente no interior do espaço nacional (Marx, 1996a, p. 250) ${ }^{3}$. Dentre os fatores que competiram para isso pode-se destacar desde dificuldades técnicas de cunhagem, em parte sanadas apenas pela invenção da prensa a vapor, no final do século XIX, até o desgaste natural das moedas metálicas e sua recorrente falsificação por parte do próprio Estado.

Desse modo, o padrão de preços tende a se dissociar de sua referência ao peso do equivalente geral, e junto com a determinação desse padrão, faz-se necessário estabelecer uma taxa de conversão entre o signo de ouro e o próprio equivalente geral. Não obstante, do emprego do papel-moeda logo se chega à emergência do papel-moeda de curso forçado, não conversível em ouro, em contextos de guerras, crises econômicas e outras conjunturas críticas que exigiam ao Estado superar seus limites orçamentários para além de sua capacidade de financiamento por meio da arrecadação de tributos e de empréstimos privados ${ }^{4}$. Dentre tantos outros momentos, no caso da Inglaterra, a conversibilidade foi suspensa no bojo das Guerras Napoleônicas, e desafiada nas crises financeiras de 1847, 1857 e 1866, sob vigência da Lei Bancária de 1844 (Gontijo, 2011, p. 10-11) que paradoxalmente buscava regrar a emissão de dinheiro sem lastro.

Ainda no âmbito da circulação simples de mercadorias, a forma-dinheiro permite a existência de um lapso entre a alienação e a aquisição, e portanto a autonomização desses dois atos, que, no entanto, são copertinentes (Marx, 1973, p. 72-73). Essa autonomização contradiz a complementaridade dos momentos do ciclo da mercadoria, abrindo a possibilidade de uma afirmação violenta de sua unidade por meio de crises (ibd, p. 132; Marx, 1977, p. 97; Marx, 1996a, p. 236). E aqui se opõe polarmente detentores de dinheiro - que corporifica o valor -, e detentores de mercadorias - que corporificam o valor de uso.

Junto com a possibilidade de descolamento entre compras e vendas, surge a possibilidade, e mesmo a "paixão de fixar o produto da primeira metamorfose" da mercadoria, a forma-dinheiro (ibd, p. 250). Com isso, o dinheiro se imobiliza em tesouro, cujo acúmulo se torna a razão de existência do "maníaco entesourador", o "capitalista demente" que se aferra à frugalidade e à avareza, condenando toda a suntuosidade e todo consumo perdulário (ibd, p. 253). No entanto, o tesouro não serve apenas para saciar a loucura do entesourador; ele também é funcional para a circulação de mercadorias, já que garante uma reserva conversível em meio de

(3) O que reforça a ilusão de seu poder discricionário absoluto de produzir os meios de troca e de controlar sua circulação. No entanto, como outrora ocorria com a moeda metálica, a emissão de papel-moeda de curso forçado não elimina os condicionantes econômicos ao qual o Estado está submetido na condição de "autoridade monetária" (Marx, 1977, p. 117).

(4) Sobre a complexa origem do papel-moeda, que não é apanágio exclusivo do Estado, cf. Shaikh (2016, cap. 5). 
circulação. Tendo se autonomizado ante as mercadorias particulares, e em certo sentido ante sua própria materialidade, agora o dinheiro adquire uma "existência autônoma fora da circulação", logrando saltar para fora dela sem se perder (Marx, 1973 , p. 152, 154, 167). E isso não apenas no tesouro, mas também na forma "estética" de objetos de luxo (Marx, 1996a, p. 253). Afora isso, o desenvolvimento do dinheiro em sua terceira determinação, de dinheiro enquanto tal, impõe a ostentação como necessidade social (Marx, 1973, p. 166).

Está-se falando, por conseguinte, do dinheiro propriamente dito, que nessa condição é a unidade de sua existência contraditória como medida de valores e como meio de circulação, superando o caráter ideal, de sua primeira determinação, e simbólico, da segunda (Marx, 1977, p. 121; Marx, 1973, p. 153; Marx, 1996a, p. 250). Além da função como meio de entesouramento, nessa terceira determinação o dinheiro exerce aqui outras duas funções fundamentais. A primeira delas decorre de necessidades práticas da circulação: os diferentes tempos de produção de cada mercadoria; o caráter sazonal de alguns produtos; as distâncias, por vezes enormes, que separam os produtores dos consumidores, ou os altos valores de uma mercadoria, que a impede de ser adquirida de uma única tacada; todos esses fatores competem para o desenvolvimento do dinheiro como "material geral dos contratos" ou como meio de pagamento. Este permite que um possuidor de mercadorias possa "apresentar-se como vendedor antes que outro como comprador" (ibd, p. 255), e que um possa comprar antes de pagar ou de concluir o pagamento, introduzindo dessa maneira as figuras do credor e do devedor. Com isso, enseja-se o estabelecimento de enormes teias contratuais.

Como meio de pagamento o dinheiro carrega propriedades de sua determinação de medida de valores (já que serve para determinar o preço da mercadoria alienada), e de seu papel como meio de circulação (permitindo a transação comercial sem se fazer de pronto presente) - atuando como "meio ideal de compra". A mediação entre os atos de compra e venda não é aqui feita diretamente pelo dinheiro: “o meio de pagamento entra na circulação, porém depois que a mercadoria já se retirou dela. O dinheiro já não media o processo. Ele o fecha de modo autônomo, como existência absoluta do valor de troca" (ibd, p. 256).

Apesar de não estarem dadas nesse momento as condições para se desenvolver a categoria dinheiro de crédito, evidencia-se que esta se ergue sobre a base do meio de pagamento (ibd, p. 259), já que o vendedor recebe em troca de sua mercadoria um "título de crédito de direito privado", que só se realizará nalgum momento do futuro, se o contrato estabelecido for respeitado. A progressiva difusão desses títulos, por meio da proliferação de redes de obrigações mútuas entre credores e devedores dispersas em infinitos pontos, que se complexificam e aumentam com o desenvolvimento do modo de produção capitalista, alteram decisivamente o volume de meios de troca em circulação, já que eles podem circular com considerável 
velocidade, e que a cada momento diversos pagamentos se compensam, dispensando a mediação de moeda (ibd, p. 258) .

A função do dinheiro como meio de pagamento, e a contribuição que ela proporciona ao processo de ampliação do alcance temporal e espacial da circulação de mercadorias, constitui mais um passo na consolidação da função do dinheiro como dinheiro mundial, que também contraditoriamente sintetiza as funções de meio de circulação e de medida de valores (Marx, 1973, p. 165; Marx, 1973, p. 155, 170; Marx, 1973b, p. 121; Marx, 1977, p. 235). Numa passagem de O Capital, Marx assevera que "o dinheiro mundial funciona como meio geral de pagamento, meio geral de compra e materialização social absoluta da riqueza em geral (universal wealth)" (Marx, 1996a, p. 262). A primeira dessas funções diz respeito à compensação dos saldos do comércio entre países, a segunda opera quando se demanda intervenção ante algum desequilíbrio persistente, e a última tem lugar quando da transferência de riqueza abstrata entre países, nos momentos em que esta não se dá na forma de outras mercadorias.

Em todos esses casos, o dinheiro como "dinheiro mundial" deveria abandonar seus nomes e roupagens nacionais, bem como qualquer tipo de traço local, limitado, e se apresentar em sua figura metálica, universal, na forma de barras de ouro e prata (ibd, p. 241-246; Marx, 1984, p. 239; Marx, 1973, p. 161). Isso porque, em âmbito nacional, o dinheiro poderia cumprir com a função de meio de troca sob a representação de um mero signo, validado socialmente pelo Estado - em termos formais, já que a validação real reside na própria função do dinheiro enquanto meio de circulação -; atuando no mercado mundial, no entanto, não existiria uma entidade nacional ou supranacional que garantisse tal validação. A contradição entre sua natureza social universal e sua realidade material natural, revela-se aqui insuperável, porém funcional (ibd, p. 170).

\section{$2 \mathbf{O}$ dinheiro como forma do capital}

Conforme indicado, para avançar na compreensão do conceito de dinheiro, faz-se necessário considerá-lo como momento do conceito de capital, que já no quarto capítulo de $O$ Capital rebaixa o dinheiro e a mercadoria a suas formas de manifestação, momentos algo evanescentes do processo de valorização do valor. Nem por isso o dinheiro é menoscabado; assim, além de uma forma necessária de

(5) Quando se estabelece uma relação mercantil mediada pelo dinheiro como meio de pagamento, este intervém apenas idealmente, e o mesmo vale para o momento em que se conclui a transação, caso isso ocorra por meio da mera compensação de pagamentos mútuos. De todo modo, existe aí um lapso entre o momento da assunção do compromisso e de seu cumprimento, que, sob certas condições, pode se transformar num abismo intransponível, caso se exija o dinheiro "vivo" num contexto em que é impossível atendê-la. Com isso, romper-se-iam inúmeras redes contratuais que definem múltiplas obrigações, e toda uma cadeia de pagamentos cairia por terra; novamente se delineia a possibilidade da crise, mas agora como crise monetária de amplo alcance (ibd, p. 257; cf. Grespan, 2008). 
existência do capital, no âmbito da produção imediata o dinheiro emerge como instrumento de mistificação e de ocultação do capital variável na forma dos salários. Ainda à guisa de exemplo, no âmbito da circulação do capital social total, por sua vez, a forma dinheiro revela-se momento decisivo do entretecimento dos vários ciclos do capital, e evidentemente não apenas abrindo e fechando o ciclo do capital monetário, de modo que o capital em geral, para existir, assume simultaneamente, a todo momento, a forma de capital monetário, de capital produtivo e de capitalmercadoria, metamorfoseando-se constantemente.

Embora não seja possível acompanhar aqui todos os passos do conceito, para os propósitos deste texto cabe considerar brevemente alguns elementos que são introduzidos quando da investigação do processo global de produção de capital, e mais especificamente da concorrência entre capitais, em que contraditoriamente se efetivam e se invertem as leis da acumulação (Marx, 1984a, p. 160; Marx, 1986, p. 278; Marx, 1973b, p. 51). Nesse âmbito, dá-se a autonomização de determinadas funções do capital, assumidas por capitais específicos; além do capital industrial, responsável pela extração da mais-valia, entram em cena o capital de comércio de mercadorias e o capital de comércio de dinheiro, que de saída perfazem atividades que visam aumentar a velocidade de circulação do dinheiro, acelerar o tempo de rotação do capital e reduzir os seus custos de circulação (Marx, 1984b, p. 238), falsos custos de produção (ibd, p. 226; Marx, 1973, p. 41, 146; Marx, 1984, p. 99-101, 255).

Os intrincados e reiterados nexos estabelecidos entre as mais diversas empresas industriais e comerciais dão azo à emergência e à generalização do crédito comercial, que passa a perfazer, até certo ponto, as funções de meio de circulação e de meio de pagamento. Esses títulos, concedidos sobretudo entre capitalistas - as letras de câmbio ${ }^{6}$-, não apenas ensejam a circulação mercantil com base em promessas de pagamento, as quais em parte eventualmente se compensam entre si, mas passam a circular de modo relativamente autônomo. Assim, o desenvolvimento do dinheiro de crédito acompanha o desenvolvimento do capital de comércio de mercadorias e de dinheiro. Tem-se que, à época de Marx, a realização de cálculos de balanços e de atos de compensação, incluindo atividades cambiais relativas ao comércio internacional, dentre outras, concentravam-se nos bancos, que também assumiam as tarefas relativas ao entesouramento - que reaparece aqui em forma especificamente capitalista -, ou seja, a necessidade que têm os capitalistas "funcionantes" de capital monetário potencial, na forma de "reserva de meios de

(6) Tendo sua existência registrada no final do século XII, demorou bastante para que as letras de câmbio se disseminassem; "quer como notas de venda a prazo, como ordens de pagamento, como certificados de depósito ou como notas promissórias emitidas por comerciantes e industriais, endossadas ou não, as letras de câmbio passaram a circular amplamente, compondo, assim como o ouro e outros títulos, o meio circulante" (Gontijo, 2011, p. 9). 
compra, reserva de meios de pagamentos, capital desocupado que, em formadinheiro, espera sua aplicação" (Marx, 1984b, p. 238). Além disso, os bancos tenderam a concentrar o capital monetário que os capitalistas adquiriam como pagamento, bem como o dinheiro ocioso de todos que dele dispõem, e também os seus rendimentos, que não são gastos de uma única vez (ibd, p. 243).

A manutenção de contas junto ao comerciante de dinheiro dá origem ao dinheiro escritural, apto a circular por meio das ordens de pagamento e cheques. Reside aqui a origem das notas bancárias, emitidas originalmente em troca do depósito de moedas metálicas, do desconto de uma letra de câmbio ou de um empréstimo sacado como "dinheiro vivo" (Klagsbrunn, 1992, p. 604). Trata-se, junto com as letras de câmbio, de dinheiro de crédito, que pode circular dentro de certas limitações: as primeiras, restritas pelo seu prazo de vencimento e pela confiança em quem a endossa; já as notas bancárias, em grande medida restritas apenas pelo "crédito social de que goza o banco emissor" (ibd, p. 605), o que explica a tendência à substituição das primeiras pelas últimas.

Nota-se que o desenvolvimento do sistema bancário permite que parte importante das transações comerciais sejam realizadas de modo estritamente contábil - o que é catapultado por inovações tecnológicas, como os cartões de crédito e as redes informatizadas em escala global -, de modo que as crescentes massas de capital monetário (potencial) concentradas nos bancos permite que estes açambarquem o oferecimento de empréstimos ${ }^{7}$. Adentramos, assim, o reino da circulação de capital enquanto dinheiro, ou da forma capital portador de juros, que se origina do potencial de investimento produtivo do dinheiro, de modo a produzir lucro (Marx, 1984b, p. 258-260). Por outro lado, abre-se também a possibilidade de uma monumental "duplicação" do "dinheiro-capital”, ou seja, da produção de capital fictício, por meio da concessão de empréstimos em montantes superiores aos de capital monetário efetivamente depositado nos bancos (o que é potencializado pela consolidação do sistema de reservas fracionárias no final do século XIX). Porém não nos adiantemos.

$\mathrm{Da}$ análise precedente depreende-se que, mesmo nos períodos em que vigorou a conversibilidade legal entre o dinheiro de papel e o ouro, isso não impediu a inconversibilidade de fato (Marx, 1973, p. 53). Ao contrário, mantida cativa de estritos limites metálicos, o modo de produção capitalista dificilmente teria se "erguido sobre seus próprios pés"; numa palavra, nessas condições o advento da grande indústria seria impossível (ibd, p. 45). Desde sempre, a reprodução ampliada do capital dependeu do comprometimento presente da riqueza abstrata a ser

(7) Sobre o processo histórico de concentração das atividades de depósito e de empréstimo pelos bancos, cf. novamente Shaik, 2016, cap. 5. 
produzida no futuro, por meio do capital portador de juros ${ }^{8}$. Logo, ainda nos primórdios das formações sociais capitalistas circulavam moedas metálicas, papelmoeda conversível e por vezes inconversível, letras de câmbio, notas bancárias das mais diversas instituições, numa complexa articulação entre a circulação de mercadorias e de capital, que de modo algum exprimiam diretamente as reservas de ouro e/ou de prata.

Ocorre que as exigências e as vicissitudes da acumulação de capital, com suas recorrentes crises econômicas e "corridas bancárias", competiram para efetivar a tendência à centralização da emissão e do controle monetário. Desse modo seria possível diminuir a insegurança dos pagamentos e o custo de determinadas transações mercantis, bem como combater o fracionamento do mercado nacional e desonerar o crédito, ao que se somava a necessidade de racionalizar o emprego dos recursos públicos e de financiar os gastos estatais em momentos críticos. Por outro lado, esse processo esteve ligado às dinâmicas e intrincadas relações entre as classes e as frações de classe proprietárias, e entre estas e o Estado, em âmbito nacional e internacional, oscilando entre o antagonismo encarniçado e a colaboração. Dito de modo simplório, em alguns países capitalistas centrais a uma grande instituição financeira ou a um relevante grupo econômico, particularmente importante como financiador do Estado, foi eventualmente dado o monopólio da emissão de bilhetes bancários ("signos circulantes de crédito", que se converteram na forma dominante de dinheiro - Marx, 1986, p. 69), havendo assim uma clivagem em relação aos demais bancos, que passaram a concentrar os depósitos e a realização de empréstimos (Klagsbrunn, 1992, p. 605).

Vê-se assim que a emergência dos bancos centrais redundou da iniciativa articulada e por vezes conflituosa entre grupos privados e o Estado, porém, como também constata Corazza (2001), as inconciliáveis contradições entre suas funções "públicas" e o imperativo do lucro, que conduzia a conflitos e opunha obstáculos ao seu engajamento na preservação de certa estabilidade monetária e ao cumprimento do papel de emprestador de última instância, levaram finalmente à sua estatização. Essa institucionalização dos bancos centrais teve características específicas em cada país, e ocorreu em ritmos muito variados, porém até o início da segunda metade do século XX os bancos centrais se generalizaram (sendo o Brasil uma exceção, cujo banco central foi formalmente criado apenas em 1964). Em todo caso, decisiva aqui foi a articulação entre as funções de "banco do governo; depois, banco de emissão e guardião das reservas; finalmente, as funções de redesconto e de emprestador de última instância" (ibd, p. 138), buscando garantir a "qualidade" do dinheiro (Brunhoff, 1978), o que singulariza os bancos centrais.

(8) Esse processo remonta até mesmo à acumulação original do capital, que teve na constituição do sistema de dívida pública um de seus momentos decisivos, imbricado ao colonialismo, e como um pressuposto da estruturação do moderno sistema de crédito (Marx, 1996b, cap. 24). 
Pela sua capacidade de engajamento em grandes transações nos mercados financeiros, e sobretudo pela possibilidade de desencadear vigorosos processos de arbitragem entre as taxas vigentes em distintas operações de curto prazo, ao determinar formalmente a taxa de juros os bancos centrais desempenham decisiva influência sobre outras relevantes taxas de mercado. Por outro lado, ao fornecer crédito e assim criar depósitos com base em depósitos existentes - mantendo certa relação entre a soma de tais depósitos e os montantes emprestados, com base nos preceitos legais determinados pelo Estado -, e por sua propensão a produzir novos instrumentos financeiros, aptos a circular até certo ponto como dinheiro, as demais instituições bancárias influenciam decisivamente a atuação do Estado, as taxas de mercado e a quantidade de capital monetário na economia. Ao mesmo tempo em que o hierárquico sistema bancário e o dinheiro escritural, os cheques, os cartões de crédito e débito etc. ensejam uma expressiva economia de meios de circulação, dentro de limites conjunturais se incrementa enormemente o fornecimento de crédito, em maior ou menor acordo com as necessidades da circulação de mercadoria e de capital (Klagsbrunn, 1992, p. 607). Desse modo, até determinado limite podese estimular o consumo e reforçar a acumulação, mas noutros contextos o resultado é uma vigorosa inflação e o reforço da tendência à produção desmedida de capital fictício e de crises econômicas.

Não cabem aqui explicações mecanicistas, mas convém constatar que os fenômenos em vista expressam e constituem a tendência contraditória à concentração e centralização do capital, inerentes ao processo concorrencial capitalista (Marx, 1996b, p. 245-338), em que os capitalistas estão condenados a ampliar seu poderia econômico e mesmo a fagocitar seus concorrentes, ou a fenecer. O avanço da subsunção real do trabalho ao capital, no bojo do processo de extração de mais-valia absoluta e sobretudo relativa, bem como o desenvolvimento do sistema creditício e dos mercados financeiros, bem como das sociedades por ações ${ }^{9}$, que catalizaram a pronta conversão de capital em dinheiro e vice-versa, são momentos chave desse processo, dando azo à constituição de grandes conglomerados empresariais, integrados vertical e horizontalmente, e atuando em escala global, definindo assim novos padrões concorrenciais, e novas formas de atuação estatal.

O sistema monetário e financeiro internacional não poderia ter permanecido incólume a essa dinâmica. Sob a vigência do padrão-ouro o grosso das políticas econômicas estava votado à defesa do valor da moeda doméstica e de relativa estabilidade monetária, e era muito restrito o leque de mecanismos que podia ser mobilizado diante de um desequilíbrio no balanço de pagamentos - basicamente, reduzia-se à manipulação das taxas de redesconto, a intervenções no mercado de câmbio, e às operações de "mercado aberto", que, no entanto, eram inviáveis em

(9) Cujos nexos também foram objeto da análise marxiana, por exemplo em Marx (1984b, p. 331-335). 
diversos países, dado o caráter pouco desenvolvido de seus mercados de bônus (Einchengreen, 2007, p. 53, p. 59-60). Pouco depois da deflagração da Primeira Guerra Mundial o padrão-ouro colapsou, e entre o fim do conflito e a formalização do Acordo de Bretton Woods o sistema monetário e financeiro internacional foi marcado por grandes vicissitudes. Obviamente, as propostas dos reformadores reunidos em Bretton Woods levaram em conta um conjunto de experiências traumáticas produzidas no período anterior, como a repressão ao comércio mundial; a hiperinflação; o desemprego em massa; o militarismo desenfreado e a guerra; os movimentos especulativos predatórios no mercado financeiro; e a depressão econômica, além da "ameaça comunista".

Como salienta Prado (2016a), diante das crises econômicas inerentes ao contraditório processo de "valorização do valor" e da necessidade de regrar os antagonismos sociais que lhe são constitutivos, via de regra, ao longo do século XX, e em meio a significativas mudanças institucionais, o intervencionismo estatal se acirrou, no sentido de fomentar a reprodução de capital. Se a "regulação financeira" no pós-Segunda Guerra Mundial foi relevante para a dinâmica de acumulação correspondente aos "anos dourados do capitalismo", a vigorosa produção de riqueza abstrata (valor) verificada à época conduziu ao fortalecimento de tendências próprias à forma capital, como a de aumento de sua mobilidade internacional e a de intensificação de seu ímpeto expansionista, relacionados à consolidação das corporações transnacionais e ao desenvolvimento dos mercados financeiros - com destaque para os mercados secundários, no bojo de uma grande onda de "inovações financeiros" e de processos de "securitização" das dívidas -, movimento esse que contribuiu com a superação dos limites impostos pelo atrelamento do dinheiro ao ouro.

Como resultado desse processo, uma forma de dinheiro ancorado à dívida estatal, mais especificamente aos títulos do Fed, tornou-se a base do sistema monetário e financeiro, assumindo funções outrora desempenhadas pelo "dinheiroouro" (Prado, 2016a); e a gestão monetária se tornou um decisivo instrumento para o fomento da acumulação, para alongar o ciclo econômico, e para manipular os efeitos das crises econômicas. Por conseguinte, a reprodução do capital tende a depender cada vez mais das intervenções estatais, e de uma promessa de valorização futura, reiterada e explosivamente descumprida. Socializam-se as perdas, adia-se e minimiza-se os efeitos imediatos dos cataclismos econômicos, mas bloqueia-se o efeito "saneador" das crises "clássicas" de sobreacumulação, que noutros momentos históricos repuseram as condições para uma vigorosa retomada da reprodução ampliada do capital. Logo, o boom mundial das finanças, bem como a proliferação de bolhas financeiras e de crises econômicas que lhe sucedeu consistem em uma "fuga para frente" do capital, diante da tendência global à queda da taxa de lucros (Jones, 2014), e da relativa limitação das opções de investimento produtivo com retorno aceitável. Trata-se, em uma palavra, de uma expressão do caráter desmedido 
da acumulação, que tende a converter os limites espaciais e temporais à acumulação em barreiras a superar (Marx, 1973, p. 277), repondo sua negatividade em um plano superior e mais geral. É esse processo que cabe perscrutar, agora à luz do debate marxista contemporâneo sobre o dinheiro.

\section{0 atual estatuto do dinheiro e o (inconcluso) debate marxista}

No interior das controvérsias sobre o atual estatuto conceitual do dinheiro, é possível identificar esquematicamente diversas posições, como a dos "neocartalistas" (cf. Wray, 1998), adeptos da já criticada concepção "convencionalista" que toma o dinheiro ("exógeno") meramente como fruto do arbítrio e como expressão do poder estatal; a daqueles que rechaçam a exposição do dinheiro de Marx como anacrônica (cf. Lavoie, 1983); a dos que sustentam que a inconversibilidade do dinheiro é, em certo sentido, um fenômeno passageiro ou ilusório (cf. Weeks, 2010, Loranger, 2013; Germer, 2002, 2005) ${ }^{10}$; e a dos autores que consideram que a perda da "lastro-ouro" corresponde efetivamente ao conceito de dinheiro, tendo como base seja a análise da forma-dinheiro, seja a das suas funções (cf. Reuten, 2005; Arthur, 2005; Williams, 2000; Saros, 2007; Lapavitsas, 2000; Foley, 1986, Moseley, 2004; Ivanova, 2013; Brunhoff, 1978; Saad-Filho, 2002; Paulani, 2014; Paulani; Rotta, 2011, Corazza, 2002, entre muitos outros), o que os conduz à busca pela atualização da crítica marxiana. Longe de considerar detidamente essas diversas posições, nas próximas páginas serão abordados uns poucos aspectos do debate, com base em análises feitas por membros dos dois últimos grupos, tendo como eixo proposições de autores brasileiros.

De saída, há de se enfatizar que a eliminação do lastro-ouro não é um acontecimento fugaz, pois o atual padrão monetário internacional possui uma maior universalidade e longevidade (sem interrupções) do que qualquer outro que tenha vigorado desde o século XIX (Einchengreen, 2007). Ademais, a inconversibilidade do dólar não constituiu uma mudança de menor monta; ao contrário, é um importante resultado da dinâmica global da acumulação de capital ${ }^{11}$. Em acréscimo, note-se que,

(10) E, em certa altura, Harvey (1982, p. 253-254), quando auspicia que diante da crescente instabilidade do sistema monetário e financeiro internacional o "padrão dólar-dólar" não perduraria, e que o dinheiro mundial haveria de se ancorar novamente em uma mercadoria alçada à condição de equivalente geral.

(11) Efetivamente, muitos anos antes de se decretar o fim da conversibilidade do dólar em ouro, "o dólar já vinha funcionando, em âmbito mundial, como meio internacional de pagamento, de transação e de reserva, constituindo-se como forma social geral da riqueza" (Prado, 2013, p. 142). Assim, o ato de Nixon sacramentou "formalmente" uma situação que já vigorava há tempos. Não obstante, a reafirmação do dólar como moeda mundial, após a eliminação dos grilhões do lastro-ouro e o "choque dos juros" - que alçou Wall Street à condição de centro do "pujante" mercado financeiro internacional; que reforçou o posto do dólar como moeda mundial e, junto com os títulos do Tesouro norte-americano, como porto seguro para investidores do mundo todo; e que potencializou o poder de senhoriagem estadunidense -, ensejou um decisivo incremento no alcance e na eficiência das políticas estatais. Com isso se explica, em parte, o êxito da atuação do Estado como emprestador de última instância, e como "garantidor do capital em última instância", buscando conter a propagação, mitigar os efeitos, e socializar os ônus das crises que se multiplicam. 
em geral, não se põe em questão a capacidade do dinheiro inconversível, e particularmente do dólar, na condição de dinheiro mundial, de desempenhar as funções de meio de circulação, de meio de pagamento, e até certo ponto de padrão de preços, e de reserva de valor em âmbito nacional e internacional (cf. Germer, 2001, p. 187-188). Entretanto, consideremos de saída alguns argumentos acerca da necessária ancoragem da forma-dinheiro à matéria ouro, relativa ao dinheiro como equivalente geral, como determinante do nível geral de preços em termos absolutos, e como medida de valores.

Segundo Germer (2005), "não existe qualquer referência em Marx à hipótese de que o dinheiro possa se tornar nalgum momento uma não-mercadoria" (p. 21), e "na conceituação de Marx, o dinheiro e o material de que é feito são a mesma coisa, uma vez que o dinheiro é o nome que se dá à mercadoria que desempenha a função de equivalente geral de valor" (Germer, 2002, p. 7). Um pouco antes, o autor havia sintetizado o debate sobre o atual estatuto conceitual do dinheiro na questão acerca da "natureza física do dinheiro na teoria de Marx, isto é, se o dinheiro deve ou não consistir em uma mercadoria" (ibd, p. 5). Ora, transcrevemos acima diversas passagens que demonstram o equívoco de se confundir a forma social com seus suportes materiais (cf. Marx, 1978, p. 78; Prado, 2013). Salientamos também que a forma-dinheiro se encontra em permanente tensão face ao seu substrato material, e em cada uma de suas determinações, o dinheiro a um tempo adere e se afasta desse substrato. Cabe acrescentar, seguindo ainda a análise mais abrangente e exaustiva de Prado (2013, p. 131-134), que a análise da mercadoria enquanto forma social e unidade contraditória de valor e valor de uso impõe a distinção entre a sua matéria (o que Germer chamou de "natureza física"), a própria forma-mercadoria, que toma a matéria como suporte, e o conteúdo dessa forma (as relações sociais que lhe são subjacentes). Identificá-los implica em perda do objeto, e enseja ilusões fetichistas (Prado, 2013, p. 136) ${ }^{12}$. Não obstante, Germer (2002) aponta corretamente para um desafio teórico: o de se explicar como um dinheiro que não possui valor intrínseco pode medir valores.

Mesmo sustentando uma tese oposta, Corrazza (2002) também incorre no erro de identificar a mercadoria com sua matéria (cf. Prado, 2013, p. 134-7), concluindo que sendo atualmente "imaterial", o dinheiro não é mercadoria, "mas pura forma imaterial do valor" (Corrazza, 1998, p. 45), tendendo desde sempre à "libertação da materialidade" (Corrazza, 1998, p. 47). Carcanholo (2002), por sua vez, também constata a tendência do dinheiro a se tornar "pura forma social" (p. 37), e que "a sociedade capitalista está sempre e cada vez mais dominada pela lógica do valor, e menos determinada pelo valor de uso" (Carcanholo, 2001, p. 38), em meio

(12) "Ouro e prata em si e por si mesmos não são dinheiro. A natureza não produz nenhum dinheiro, da mesma maneira que não produz taxa de câmbio ou banqueiros” (Marx, 1973, p. 177); a função de equivalente-geral, que em certa altura foi assumida pelos referidos metais, emerge historicamente do processo social. 
a um processo de "desmaterialização da riqueza" (Carcanholo, 2001, p. 38), o que corresponderia ao processo de "substantivação do dinheiro" (Carcanholo e Nakatani, 2001). A despeito das diferenças de suas abordagens, Corrazza e Carcanholo de certo modo parecem endossar aqui a tese desenvolvida por Paulani (1991), segundo a qual a dimensão formal do dinheiro sempre fora precípua, e tenderia a superar seu conteúdo material ${ }^{13}$; segundo a autora, a universalização do dinheiro inconversível seria, portanto, um desenvolvimento necessário ("lógico" e "ontológico") de seu caráter fetichista, que saltaria à vista diante da ruptura com o padrão "dólar-ouro" (p. 175). Em suas palavras, "o dinheiro é essencialmente forma", "forma autonomizada do valor" (Paulani, 1991, p. 144), de modo que "sua matéria é pura forma” (p. 162). Mais recentemente, junto com Rotta (2009), Paulani afirma que o dinheiro inconversível é uma "nova determinação", e uma "forma particular" do dinheiro, e "é só como forma pura, dinheiro inconversível, que a forma dinheiro se torna adequada ao seu conceito", superando as "inadequações da forma dinheiro com materialidade no ouro" (Paulani; Rotta, 2009, p. 612), e resolvendo a contradição da "moeda do padrão-ouro", "entre o fato de ser ouro e de ser uma relação social", ao repô-la "como o fato de ser moeda nacional e internacional ao mesmo tempo" (Paulani; Rotta, 2009, p. 629). Esse desenvolvimento só se fez possível com o advento da "hegemonia norte-americana", já que "sem o Estado, a forma inconversível do dinheiro não teria lugar, pois sua formação contraditória ou ficaria a descoberto ou nem mesmo se efetivaria" (p. 615).

Remetendo a Moseley (2004) e Foley (2005), que teriam fornecido a "melhor resposta" ao problema do dinheiro inconversível como medida de valores, Paulani (2014) considera que o dólar tem seu valor determinado "por ser a unidade na qual o débito do governo americano é nominado" (p. 788). Tal proposição se afigura problemática, afinal os títulos da dívida estatal estadunidense tampouco possuem valor. Ocorre, assevera Paulani (2014), que a propensão do dólar de servir como medida de valores redundaria de uma espécie de propriedade atávica, um "traço de valor ancestral" que o ouro teria legado aos títulos norte-americanos, já que sai o ouro mas fica o sistema de permutabilidade universal do qual ele era peça fundamental, agora com esteio nos referidos títulos (p. 788).

Ao menos à primeira vista, essa tese parece, de certo modo, reabilitar um conjunto de proposições corretamente criticadas por Paulani e Rotta (2009). Segundo Brunhoff (1978), “o problema dos preços”, referente à formação e às variações dos preços relativos e do nível geral de preços "não é, em Marx, um problema monetário, uma vez estabelecida a gênese do equivalente geral” (p. 89). Esse tipo de explicação sobre o dinheiro inconversível de certa forma busca circunscrever a importância da mercadoria monetária ao processo de gênese do dinheiro, e por vezes vem

(13) Carcanholo (2001), ao contrário de Corrazza e Paulani, identificou aí uma tendência não plenamente consumada. 
acompanhado de uma demonstração matemática acerca da independência que a formação dos preços relativos das mercadorias guarda em relação ao dinheiro em sua determinação como medida de valores, como ocorre em Lapavitsas (2000) e Saad-Filho (2002, p. 98-99). Esses autores lançam o foco de suas investigações sobre o estatuto teórico do dinheiro inconversível na esfera da concorrência, na qual se conformam os preços de produção, o que faria com que a questão da conversibilidade ou inconversibilidade do dinheiro se tornasse irrelevante (cf. também a contribuição de Arthur, 2005); com isso, pretendem "responder uma pergunta com uma resposta de outra pergunta" (Paulani; Rotta, 2009, p. 622). Para Rotman (1987), ao passar de símbolo a signo o dinheiro já apresentaria uma potencial autoreferencialidade, que culminaria no atual dinheiro inconversível (p. 5). Por outro lado, Moseley (2004) argumenta que a necessidade de a medida dos valores possuir, ela mesma, um valor "é uma contingência histórica, e não uma necessidade teórica" (p. 17), e, grosso modo, sustenta que o dinheiro pode cumprir suas funções na medida em que os "agentes" o reconheçam enquanto tal (cf. também Reuten, 1995, p. 108; e Ivanona, 2013 , p. 45 , segundo a qual "o dinheiro não precisa de modo algum ser uma mercadoria"). Desse modo, esses autores tombam na ilusão convencionalista. Noutra obra, Lapavitsas (2005) argumenta que os aspectos funcionais do dinheiro absorveriam seus aspectos materiais, de tal forma que um pedaço de papel que na prática exerça o "monopólio da habilidade de comprar" seria tão dinheiro quanto fora o ouro, noutras épocas. Foley (1986), Saros (2007) e Moseley (2004) também concluem que o valor do dinheiro inconversível é dado pelo seu poder de compra. Porém, com isso não se fornece uma resposta teórica à questão; numa espécie de recaída à Teoria Quantitativa da Moeda, apresentam um mecanismo tautológico para estabelecer a relação entre a massa de meio circulantes e os valores das mercadorias que eles deveriam exprimir, que serve tanto para o dinheiro conversível quanto para o inconversível (conforme constatam Paulani; Rotta, 2009, p. 620; Prado, 2016b, p. 2; Weeks, 2010, p. 81). Carcanholo (2001) também invoca o "poder de compra do padrão monetário", ao lembrar que uma determinada estrutura de preços relativos "é dependente de parâmetros definidos pela tecnologia e dos critérios de apropriação vigentes", e que em seu interior o dinheiro inconversível também teria determinado o seu "poder de compra", independentemente da mediação áurea, o que lhe permitiria assim medir valores (p. 40-41).

Apesar dos méritos da explicação (onto)lógica desenvolvida por Paulani (2014), cujo rigor faz com que se destaque no interior do debate internacional, ela parece insuficiente para dar conta da "natureza qualitativa do dinheiro-papel" (Prado, 2013, p. 139). E talvez se insinue aí uma discordância teórica de fundo: aponta-se com correção que existe certa "preponderância" da forma sobre a matéria, e, de fato, viu-se que a tendência à autonomização da forma dinheiro havia sido apreendida por Marx, e se encontra no cerne do desenvolvimento dessa forma, e também da formacapital. No entanto, a despeito dessa tendência, que faz com que o capital subsuma 
suas formas concretas de manifestação, essa autonomização encontra limites insuperáveis, e apesar de constituir-se enquanto totalidade formal, o capital permanece dependente do trabalho vivo: sua substância lhe permanece exterior, o que o impede de se erguer como totalidade substancial ${ }^{14}$. Em contraste, a totalidade hegeliana se constitui por meio da “elevação da 'substância' real a 'sujeito' através da reflexão, do dobrar-se sobre si dessa substância, que não só se determina como se autodetermina" (Grespan, 2002, p. 42); grosso modo, a contradição fundamental do Sujeito Absoluto eleva-se à condição de contradição "para-si”, fundando novas realidades, e tendendo à realização plena da liberdade, enquanto que a contradição que fundamenta o "sujeito-capital" permanece "em-si", o que impõe sua "tendência crônica ao desmedido" (Grespan, 2002, p. 43), à reificação universal e à barbárie ${ }^{15}$. Como corolário, o capital não logra converter-se numa "pura forma"; teria o dinheiro realizado esse feito?

\section{Um caminho para a solução de algumas controvérsias}

Assim como Paulani (2014), ao analisar a atual configuração do dólar Prado (2013, 2016a, 2016b) procura apresentar uma resposta dialética, de acordo com a qual, atualmente, o dinheiro enquanto moeda mundial possui e não possui valor possui um valor fictício -, e nesse sentido ele introduz o conceito de "dinheiro fictício" - "uma forma de valor que "não' possui valor, pois apenas o representa" (Prado, 2013, p. 139) -, estabelecendo uma analogia com o conceito de capital fictício, "uma representação nominal de capital inexistente"; "mesmo não sendo

(14) É elucidativa a passagem em que Marx expõe a importância do dinheiro-ouro e prata justamente como decorrência do processo (fetichista) de autonomização do capital: "Certo quantum de metal, insignificante em comparação com a produção global é reconhecido como eixo do sistema [...]. Mas, por meio de que se distingue o ouro e a prata das outras configurações da riqueza? Não é pela grandeza do valor, pois esta é determinada pela quantidade do trabalho neles objetivado. Mas como encarnações autônomas, expressões do caráter social da riqueza. Essa sua existência social aparece, pois, como algo do além, como coisa, como objeto, mercadoria, ao lado e por fora dos elementos reais da riqueza social. Enquanto a produção flui, isso é esquecido. O crédito, como forma igualmente social da riqueza, expulsa o dinheiro, e usurpa seu lugar. [...] Mas, tão logo o crédito é abalado - e essa fase sobrevém sempre, necessariamente, no ciclo da indústria moderna - pretende-se que toda riqueza real seja efetiva e subitamente transformada em dinheiro, em ouro e prata, uma existência louca, mas que necessariamente emana do próprio sistema. E todo o ouro e prata, que devem bastar para essas exigências imensas, limita-se a alguns poucos milhões nos porões do Banco" (Marx, 1986, p. 92-93).

(15) Há de se considerar assim a rigorosa oposição entre a dialética marxiana e a hegeliana, e o caráter eminentemente "crítico e revolucionário" da primeira, que "inclui no entendimento positivo do existente ao mesmo tempo também o entendimento de sua negação, de seu declínio necessário" (Marx, 1996a, p. 141). Ao invés da insossa ideia de meramente colocar em pé o que estava de ponta cabeça, cumpre considerar efetivamente a relação entre a forma e o conteúdo visados, ambos reciprocamente transtornados, como exige a dialética. A tão propalada "inversão materialista" de Marx não consiste apenas em abandonar o "plano das ideias" em favor das relações supostamente "concretas" (até porque as categorias da economia política, criticada por Marx, expressam "formas de ser"). Ao visar a forma capital, e não a Lógica, tanto a "semântica" quanto a "sintaxe" dialética são inevitável e radicalmente modificadas: a dialética redunda da imersão em um objeto contraditório e responde ao movimento desse objeto. Nesse sentido, Marx foi um dialético consequente. 
efetivamente real, o capital fictício é negociável como se o fosse, ou seja, ele 'circula normalmente como valor-capital"” (ibd, p. 148). Como se viu, trata-se de um "nãocapital", de determinados títulos de propriedade ou títulos de dívida pública ou privada que mesmo sem valor são precificados (por meio da "capitalização"), e circulam de modo independente do movimento do "capital real" ou dos fundos estatais que lhes serviriam de base, mas que se encontram em permanente relação de equivalência com o "capital real" (ibd, p. 144). Por seu turno,

O valor fictício do dinheiro-papel oficialmente inconversível está também numa relação de equivalência - que se impõe tendencialmente por meio de flutuações sempre que a emissão não seja excessiva - com o valor real do ouro, por meio do mercado de ouro/. Assim se explica como o dinheiro mundial inconversível, mesmo 'não' sendo valor, é capaz de medir valor (ibd, p. 144).

Com isso, revela-se que "a concepção de Marx de dinheiro mundial é historicamente datada, mas também possui um fundo teórico que é irrecusável" (ibd, p. 144). De fato, apesar de curto e aparentemente despretensioso, o referido texto de Prado se afigura como uma relevante contribuição ao debate em questão. Não obstante, cabe recordar que, ao tratar do capital fictício, a ênfase de Marx parece recair no sentido da autonomização, no permanente afastamento em relação ao capital do qual o capital fictício é título. Assim como ocorre com a separação entre compra e venda ensejada pela forma dinheiro em sua determinação de meio de pagamento; com a desproporção entre os departamentos, ao longo do processo de circulação de capital; com a negação do trabalho vivo pelo trabalho morto, no bojo do aumento da composição orgânica do capital, que se exprime na tendência à queda da taxa de lucros - entre tantos outros momentos próprios ao processo global de produção capitalista -; também aqui, dizíamos, no que tange ao capital fictício, esse processo de autonomização de momentos copertinentes vai até o ponto em que a unidade se afirma de modo violento por meio de crises - como as que pulularam pelo mundo nas últimas décadas, tendo como estopim o estouro de bolhas financeiras (Mello, 2013).

Sob certas conjunturas, o ouro, bem como outras mercadorias, como os imóveis, parecem se erigir em portos seguros diante de abalos no processo de acumulação, tanto nos casos de crises deflacionárias, quanto nos momentos em que o dinheiro "enfraquece", em meio a determinados processos inflacionários. Ademais, o comércio de tais mercadorias é alvo de periódicos e intensos processos especulativos, o que dificulta a realização de uma análise comparativa entre as evoluções do mercado de ouro e de dólar, no intuito de perscrutar a "equivalência intrínseca" entre o dinheiro-mundial e o ouro (que se revela não apenas nas vicissitudes do mercado de ouro, mas também na persistência do ouro como reserva de valor e como meio de pagamento internacional, o que evidentemente o distingue do petróleo e de quaisquer outras commodities). Essa dificuldade em localizar 
empiricamente os nexos entre o ouro e o dólar inconversível provém do "caráter anárquico" da produção capitalista, como argumenta Prado (2013, p. 152), mas também da tendência ao afastamento entre as formas fictícias do capital e aquelas das quais derivam ${ }^{16}$.

Diante do exposto, compreende-se como o dinheiro fictício exerce a função de padrão de preço, bem como de meio de circulação, de pagamento e de entesouramento, e no caso do dólar estadunidense, de dinheiro mundial, apesar de o "poder de compra do meio de circulação" se tornar instável, "pois passa a depender do poder discricionário de um banco central que não controla e não pode controlar o funcionamento do sistema econômico como um todo" (Prado, 2016a, p. 25). Contudo, por não ter em si trabalho abstrato objetivado, o dinheiro inconversível criado a partir dos títulos da dívida estatal (o capital fictício) e multiplicado pelo sistema bancário e financeiro de modo geral - é incapaz de perfazer a função de equivalente geral e de medida de valores (ibd, p. 25). Dito com maior precisão, a determinação do dinheiro como medida de valores "não desapareceu, mas foi recalcada no funcionamento cada vez mais anárquico do sistema capitalista" (Prado, 2016b, p. 9). Logo, se o movimento do capital logra uma resolução, ao menos parcial, da contradição entre a forma e a matéria do dinheiro, isso se dá ao custo de uma ruptura na longa cadeia de determinações e processos que constituem e sustentam a lei do valor, e esse ponto deve ser destacado. Como novamente assevera Prado, "o valor-trabalho é uma regulação sistêmica inerente ao modo de produção capitalista em seu funcionamento cego" (Prado, 2013, p. 148), atuando em escala global e regional (de modo nada harmonioso) como elemento ordenador, relacionado à divisão do trabalho social nos diferentes ramos produtivos, ao ritmo das inovações tecnológicas e organizacionais, ao grau de concentração e centralização do capital, e assim por diante. A existência de uma mercadoria monetária, como se argumentou acima, era um elemento basilar dessa dinâmica, de tal forma que a universalização do dinheiro inconversível parece competir para a erosão de certos marcos regulatórios da lei do valor, tornando a dinâmica da acumulação mais adequada às exigências de sua proeminente dimensão financeira, porém ainda mais instável e explosiva. Em particular, é evidente, essa condição torna o dinheiro, elemento tão

(16) Não obstante, são abundantes os estudos econométricos que buscam demonstrar a correlação entre o ouro e o dólar norte-americano; para um exemplo no interior do campo marxista, cf. Loranger (2013), tratando da relação entre o preço do ouro e a inflação nos Estados Unidos, bem como a evolução da demanda por ouro. Weeks (2010) também analisa estatisticamente a questão, tendo por referência o fenômeno da inflação. Conforme a argumentação ora proposta, ambos se equivocam em ignorar a ruptura que autonomização da forma capital promoveu entre a forma-dinheiro e seu "lastro", dando origem ao "dinheiro fictício". Outra contribuição digna de nota aqui é a de Shaikh (2016), que busca demonstrar por meio de uma análise empírica que o fenômeno da inflação crônica (e por vezes explosiva) emergiu somente após a derrocada definitiva do "gold exchange standart", em meados da década de 1930, e com as novas formas de atuação estatal que emergiram a partir da "economia de comando", tal qual constituída em meio à Primeira Guerra Mundial, e da Grande Depressão da década de 1930. Até então, em meio a importantes oscilações, e à luz da experiência do pós-Segunda Guerra Mundial, o nível geral de preços apresentou considerável estabilidade. 
essencial do metabolismo econômico capitalista, mais vulnerável às vicissitudes do mercado mundial, incluindo o jogo geopolítico internacional.

Não é possível desenvolver essa análise nos limites desse texto, e tampouco distinguir adequadamente entre distintos padrões de internacionalização, de organização e de desenvolvimento tecnológico da produção verificados ao longo do século XX e nesse início de século XXI, porém, conforme mencionado, tais desenvolvimentos foram acompanhados pela intensificação do intervencionismo estatal, que em suas múltiplas dimensões, e mobilizando variegados mecanismos, competiu para estimular a acumulação, bem como para postergar e controlar os efeitos da crise deflacionária, direcionando seus ônus para os capitais de menor peso econômico e político, e sobretudo para os ombros da população trabalhadora. Dito de maneira apressada, as políticas econômicas estatais progressivamente se afirmaram como motor da acumulação e também como fator anticíclico. Mais recentemente, e tendo seu ápice na crise mundial deflagrada em 2007-8, tornou-se patente o alcance das políticas de salvamento e a atuação do Estado e dos bancos centrais não apenas como emprestadores de última instância, mas também criando mercados para os títulos podres que corroíam os balanços de grandes grupos econômicos, e inundando o mercado mundial com crédito barato e abundante, por meio da produção de capital fictício. A despeito desses esforços, que resultam na elevação do endividamento estatal a níveis cada vez mais monumentais, não se dirimiu a tendência à formação de bolhas financeiras, e as taxas de crescimento mundial continuam bastante baixas, expressão de taxas de lucro e de acumulação que de modo algum se recuperaram de modo vigoroso (Roberts, 2016). Deixando de lado o debate sobre os determinantes dessa acumulação de capital claudicante, o fato é que a dinâmica capitalista segue numa toada em que a vigorosa centralização verificada é pouco acompanhada pelo movimento da concentração de capital $\left(\right.$ Chesnais, 2016) ${ }^{17}$. Nesse contexto, novas e violentas crises se anunciam, ao mesmo tempo em que se esgota a capacidade de resposta estatal, nos moldes das que foram dadas nas últimas décadas.

\section{Considerações finais}

Como demonstrou Prado (2016a), o desenvolvimento histórico capitalista, que inclui constantes reconfigurações do Estado e do sistema interestatal, primeiro

(17) Em um contexto em que o capital segue reinando sem rivais, compreende-se assim a sua crescente voracidade no sentido de destruir as políticas sociais universalizantes e os direitos trabalhistas, de modo a rebaixar os custos da força de trabalho, ampliar as jornadas de trabalho e elevar sua intensidade; de privatizar as instituições e os serviços estatais, bem como de converter em mercadoria os chamados "bens públicos", o genoma, e assim por diante; de reduzir a taxação sobre as grandes fortunas e sobre os rendimentos do capital; de promover políticas de "austeridade" de modo a gerar superávits primários que são direcionados à remuneração do capital portador de juros e do capital fictício, dentre outras. Nem assim parecem estar sendo abertas frentes sólidas para a reprodução ampliada do capital em escala mundial. 
relegou o dinheiro-ouro ao papel de reserva monetária, trancafiado nos cofres dos bancos centrais, e de pretenso porto seguro ante as crises econômicas que colocavam em xeque o sistema creditício; e depois tornou o dinheiro inconversível de curso forçado a referência do sistema monetário e financeiro, inclusive em escala internacional (neste caso, tendo esteio nos títulos da dívida pública norte-americana que, como todo capital fictício, presentifica uma suposta extração e realização futura de mais-valia em escala ampliada, e um aumento esperado na arrecadação, mas que adquire um movimento autônomo). Prevalece desse modo o dinheiro fictício, destacado momento da atual proeminência do capital fictício. Apesar desse processo extrapolar o horizonte histórico analisado por Marx, buscou-se evidenciar que sua compreensão depende do recurso à apresentação marxiana do dinheiro, que deve ser considerada à luz do evolver histórico.

Afirma-se assim a importância da crítica à forma-valor, tomada pela maioria dos economistas como uma fantasmagoria obsoleta, e não como o que de fato é: uma fantasmagoria real, uma relação social fetichista que fundamenta, regula e organiza as relações econômicas capitalistas. Em tempos de prosperidade, pode-se dar vazão ao indolente e cômodo ímpeto de se ater à superfície dos fenômenos econômicos, próprio do positivismo que impera em boa parte da ciência econômica. No entanto, diante de episódios como a mais recente crise mundial, em que se rompem os consensos, quebram-se as promessas harmoniosas e os decretos de "fim da história", e se abala a jactância especializada, impõe-se a busca pelos fundamentos contraditórios do modo de produção capitalista, e a adoção do "ponto de vista da totalidade" (Lúkacs, 2003, p. 105). Evidenciam-se aí os limites do mainstream econômico, já que, como demonstrou Grespan (2008), a crise é o negativo do capital, forma de manifestação de suas contradições, e ao mesmo tempo o modo como estas se movem e se reproduzem numa escala superior. Sua análise revela o caráter singular das formações sociais capitalistas e explicita sua historicidade, obnubilada contumaz e sistematicamente pelos apologistas da "ordem". Desse modo, essa investigação não pode dispensar uma análise abrangente do processo de subjetivação do capital, superando os limites da circulação imediata do capital, e que tem na forma valor um momento fundamental.

De resto, há de se reconhecer o caráter inconclusivo dessas notas, com a esperança que isso não invalide de todo o esforço realizado, no sentido de contribuir com esse relevante e aberto debate.

\section{Referências bibliográficas}

ARTHUR, C. J. Value and money. In: MOSELEY, F. (Ed.). Marx's theory of money: modern appraisals. Basingstoke, Reino Unido: Palgrave Macmillan, 2005.

BRUNHOFF, S. A moeda em Marx. Rio de Janeiro: Paz e Terra, 1978. 
CARCANHOLO, R. O capital especulativo e a desmaterialização do dinheiro. Revista da SEP, Uberlândia, MG, v. 8, p. 26-45, 2001.

CARCANHOLO, R. Sobre a natureza do dinheiro em Marx. Revista da SEP, Uberlândia, MG, n. 11, p. 33-37, 2002.

CARCANHOLO, R.; NAKATANI, P. Capital especulativo parasitario versus capital financiero. Revista Problemas del Desarrollo, México, v. 32, n. 124, p. 9-31, 2001.

CARCHEDI, G. Frontiers of political economy. New York: Verso, 1991.

CHESNAIS, F. Finance capital today: corporations and banks in the lasting global slump. Leiden: Brill, 2016. (Historical Materialism Book Series).

CORAZZA, G. O dinheiro como forma do valor. Revista da SEP, Uberlândia, MG, n. 11, 2002.

DE ROOVER, R. Money, banking, and credit in medieval bruges. The Journal of Economic History, v. 2, n. 1, p. 52-65, 1942.

EINCHENGREEN, B. A globalização do capital: uma história do sistema monetário internacional. São Paulo: Editora 34, 2007.

FAUSTO, R. Dialética marxista, dialética hegeliana: a produção capitalista como circulação simples. São Paulo: Paz e Terra, 1997.

FOLEY, D. K. Understanding capital: Marx's economic theory. Cambridge: Harvard University Press, 1986.

GERMER, C. The commodity nature of money in Marx's theory. In: MOSELEY, F. (Org.). Marx's theory of money: modern appraisals. Basingstoke, Reino Unido: Palgrave Macmillan, 2005.

GERMER, C. O caráter de mercadoria do dinheiro segundo Marx. Revista da SEP, Uberlândia, MG, n. 11, 2002.

GONTIJO, C. Os mecanismos de funcionamento do "padrão ouro": uma visão crítica. Belo Horizonte: Cedeplar/UFMG, 2011. (Texto para Discussão, n. 435).

GRAEBER. D. Debt: the first 5,000 years. New York: Melville House Printing, 2011.

GRESPAN, J. L. O negativo do capital. São Paulo: Expressão Popular, 2008.

GRESPAN, J. L. A dialética do avesso. Crítica Marxista, Campinas, SP, v. 1, n. 14, p. 26-47, 2002.

GRESPAN, J. L. As formas da mais-valia: concorrência e distribuição no Livro III de $O$ capital. Crítica Marxista, Campinas, SP, n. 33, p. 9-30, 2011. 
HARVEY, D. The limits to capital. Oxford: Basil Blackwell, 1982.

IVANOVA, M. M. The dollar as world money. Science \& Society, v. 77, n. 1, p. $44-$ 71,2013 ,

JONES, P. The falling rate of profit and the great recession. Tese (Doutorado)Departamento de Economia, Australian National University, 2014.

KLAGSBRUNN, V. H. Considerações sobre a categoria dinheiro de crédito. Ensaios FEE, Porto Alegre, n. 13, v. 2, 1992.

LAPAVITSAS, C. Money and the analysis of capitalism: the significance of commodity money. Review of Radical Political Economics, Arlington, Texas, v. 32, n. 4, 2000.

LAVOIE, D. Some strenghts in Marx's disequilibrium theory of money. Cambridge Journal of Economics, Cambridge, Mass., n. 7, 1983.

LORANGER. J-G. Did gold remain relevant in the post-1971 international monetary system? Research in Political Economy, Binkley, UK, v. 28, 2013.

LÚKACS, G. História e consciência de classe. São Paulo: Martins Fontes, 2003.

MARX, K. Elementos fundamentales para la crítica de la economía política (borrador). Buenos Aires: Siglo Veintiuno, 1973. v. I.

MARX, K. Contribuição à crítica da economia política. São Paulo: Martins Fontes, 1977.

MARX, K. O capital: crítica da economia política. São Paulo: Nova Cultural, 1996a. Livro I, Tomo I. (Coleção Os Economistas).

MARX, K. O capital: crítica da economia política. São Paulo: Nova Cultural, 1996b. Livro I, Tomo II. (Coleção Os Economistas).

MARX, K. O capital: crítica da economia política. São Paulo: Victor Civita, 1986. Livro III, tomo V. (Coleção Os Economistas).

MARX, K. O capital: crítica da economia política. São Paulo: Victor Civita, 1984a. Livro II. (Coleção Os Economistas).

MARX, K. O capital: crítica da economia política. São Paulo: Victor Civita, 1984b. Livro III, tomo IV. (Coleção Os Economistas).

MARX, K. Capítulo sexto inédito de O Capital: resultados do processo de produção imediata. Porto: Publicações Escorpião, 1978.

MELLO, G. M. C. Subconsumo ou sobreacumulação? Debate teórico e político para análise da crise atual". Crítica Marxista, Campinas, SP, n. 37, 2013. 
MOLLO, M. L. R. The endogeneity of money: pos-Keynesian and Marxian concepts compared. Research in Political Economy, Bradford, Reino Unido, v. 17, 1999.

MOSELEY, F. The "monetary expression of labor" in the case of non-commodity money. South Hadley, Massachusetts, Mount Holyoke College, 2004. (Working Paper).

PAULANI, L.M. Do conceito de dinheiro e do dinheiro como conceito. Tese (Doutorado)-FEA-USP, São Paulo, 1991.

PAULANI, L. M. Money in contemporary capitalism and the autonomisation of capitalist forms in Marx's theory. Cambridge Journal of Economics, Cambridge, Mass., n. 38, 2014.

PAULANI, L. M. Acumulação e rentismo: resgatando a teoria da renda de Marx para pensar o capitalismo contemporâneo. In: ENCONTRO NACIONAL DE ECONOMIA POLÍTICA, 17, Campinas, 2012. Anais...

PAULANI, L. M.; ROTTA, T. N. A teoria monetária de Marx: atualidade e limites frente ao capitalismo contemporâneo. EconomiA, Niterói, RJ, v. 10, n. 3, p. 609-633, 2009.

PRADO, E. F. S. (Neo)liberalismo: da ordem natural à ordem moral. Outubro, São Paulo, v. 18, p. 149-174, 2009.

PRADO, E. F. S. Da controvérsia brasileira sobre o dinheiro mundial inconversível. Revista da Sociedade Brasileira de Economia Política, Niterói (SEP), Niterói, RJ, n. 35, p. 129-152, 2013.

PRADO, E. F. S. From gold money to fictitious money. Brazilian Journal of Political Economy, São Paulo, v. 36, n. 1 (142), p. 14-28, 2016 a.

PRADO, E. F. S. Dinheiro: medida dos valores e padrão dos preços, [s.n.t.] $2016 \mathrm{~b}$. Disponível em: https://nunomiguelmachado.files.wordpress.com/2012/01/artc2badinheiro-medida-valores-e-prado.pdf.

REUTEN, G. Money as constituent of value. In: MOSELEY, F. (Ed.). Marx's theory of money: modern appraisals. Basingstoke, Reino Unido: Palgrave Macmillan, 2005.

ROBERTS, M. The long depression: Marxism and the global crisis of capitalism. Chicago: Haymarket Books, 2016.

SAAD-FILHO, A. The value of Marx: political economy for contemporary capitalism. London: Routledge, 2002.

SABADINI, M. S. Especulação financeira e capitalismo contemporâneo: uma proposição teórica a partir de Marx. Economia e Sociedade, Campinas, v. 22, n. 3 (49), p. 583-608, 2013. 
SAROS, D. E. The price-form as a fractional reflection of the aggregate value of commodities. Review of Radical Political Economics, Thousand Oaks, Califórnia, v. 39, 2007.

SHAIKH, A. Capitalism: competition, conflict, crises. New York: Oxford University Press, 2016.

USHER, A. P. The early history of deposit banking in Mediterranean Europe. Cambridge: Harvard University Press, 1943.

WEEKS, J. The theoretical and empirical credibility of commodity money. Science \& Society, New York, v. 76, p. 66-94, 2010.

WILLIAMS, M. Why Marx neither has nor needs a commodity theory of money. Review of Political Economy, Abingdon, United Kingdom, v. 12, p. 435-451, 2000.

WRAY, L.R. Understanding modern money. United Kingdom: Edward Elgar, 1998. 